\title{
PONER EN MARCHA LA VERDAD: EMILE ZOLA Y LA NOVELA SOCIAL EN CHILE
}

\author{
TO PUT TRUTH IN PLACE: EMILE ZOLA \\ AND THE SOCIAL NOVEL IN CHILE
}

\section{JAIME GALGANI²}

\section{RESUMEN}

Emile Zola, fundador del naturalismo, como autor moderno, genera un proyecto ambicioso que es recepcionado en Chile a nivel de crítica literaria, ubicándolo en el contexto de la "novela social". Su propuesta, consistente en reflejar la realidad en la literatura y dar cuenta de los vicios sociales, es recibida en Chile de distintas maneras y siempre vinculándola a la personalidad y los compromisos del escritor. Desde Balmaceda Toro hasta Augusto D'Halmar, testigos incuestionados de la época, y revisando algunas revistas literarias de inicios del siglo XX, se presenta, en tres fases, el panorama general de dicha recepción con la finalidad de definir la importancia que en el campo literario chileno tuvo el escritor francés.

Palabras clave: Novela social, naturalismo, campo literario, crítica literaria, revistas.

\section{ABSTRACT}

Emile Zola, as a modern writer and the founder of naturalism, generated an ambitious project that was received in Chile on the level of literary criticism, which placed it in the context of the "social novel". His proposal, consistent with the reflection of reality in literature and the revelation of social vice was received in Chile in different ways but always linked to the personality and commitments of the writer. From Balmaceda Toro to Augusto D'Halmar, witnesses of the period, and on revision of some literary magazines of the early $20^{\text {th }}$ century, we find presented in three phases a general panorama

${ }^{1}$ Este artículo forma parte de la investigación realizada por el profesor Jaime Galgani en el proyecto que preside: iniciación Fondecyt No 11090054, "Literatura chilena y proyecto cultural en revistas de inicio del siglo XX (1900-1910)".

${ }^{2}$ Doctor en Literatura, académico Departamento de Humanidades Universidad Católica Silva Henríquez. Santiago, Chile. E-mail: jgalganim@ucsh.cl 
of Zola's reception allowing us to define the importance of the writer on the Chilean literary scene.

Keywords: Social novel, naturalism, literary field, literary criticism, journals.

Recibido: 11.11.10. Aceptado: 25.03.11.

\section{INTRODUCCIÓN}

ON EL LEMA "Mettre in marche la verité" se titula este artículo para presentar la discutida recepción de uno de los escritores más influyentes en la producción literaria de comienzos del siglo XX en Chile. En efecto, Emile Zola, escritor francés, fundador de la escuela naturalista, produjo, como en todas partes, también entre nosotros admiraciones y rechazos. Y es precisamente el propósito fundamental de este artículo revisar algunas lecturas e interpretaciones que se hicieron de él. De él y de su obra, de él y de su proyecto estético, pues, inevitablemente, ambos van unidos, de manera similar a lo que ocurrió con el escritor ruso León Tolstoi.

La exploración de textos literarios comienza con la revisión de los planteamientos del joven intelectual Pedro Balmaceda Toro, quien, como conductor de un proceso de renovación en el campo literario en la década de los '80 del siglo XIX, y uno de los que más contribuyó a que Zola se leyera en Chile, su voz resulta claramente pertinente; él testimonia la voz de una década y la vitalidad de una visión que comienza a diseñar derroteros distintos para la literatura chilena.

En segundo lugar, se consideran algunos de los pocos comentarios encontrados en pequeñas revistas de inicios del siglo XX (1900-1910), período en que se centra el proyecto de investigación en que se radica esta investigación. No hay muchas columnas sobre Zola, pero ellas permiten ver qué se está valorando más a esas alturas: el autor o su obra.

En tercer lugar, en el otro extremo temporal, se revisa brevemente una semblanza que Augusto D'Halmar publicó hacia 1948, en su libro Los 21. La figura de Zola, para entonces, ya ha asumido un perfil definitivo.

Tres etapas, en síntesis: aparición de Zola en las letras chilenas (18801889), consagración de la fama del escritor y su obra (1900-1910), memoria y perfil hacia 1948. Y, en los extremos históricos del periodo, el testimonio de dos actores fundamentales del proceso de autonomización del campo literario en Chile (Pedro Balmaceda Toro y Augusto D'Halmar).

La metodología exploratorio-descriptiva se combina con la reflexiva, puesto que se quiere formular un cuadro general en el cual se encaje lo 
más certeramente posible el rol de Zola en el campo literario, ya sea por su recepción crítica como por su influencia en los escritores chilenos. Como trasfondo, está la teoría de campo de Pierre Bourdieu. Metodológicamente, además, se tiene en cuenta que, al período de inscripción de la lectura de Zola en Chile considerado en este artículo, corresponde la concepción moderna del autor, la que lo considera como artífice y conductor de un dinamismo de producción, protagonista de un proceso orientado a comunicar una "verdad" al lector. Coincidente con la monumentalidad y peso de la figura del autor, está también la concepción de la literatura al servicio de una causa determinada; en este caso, la cuestión social.

\section{BALMACEDA TORO Y ZOLA}

Para comprender el tono general de la recepción de Zola durante la década que va de 1880 a 1890 , es necesario recurrir a los extensos comentarios que Pedro Balmaceda Toro realiza y que pueden ser leídos en la publicación de sus Estudios i ensayos, recopilación póstuma llevada a efecto por A. de Gilbert y publicados hacia 1889. En dichos ensayos se advierte una dominante temática que responde a las valoraciones narrativas de la época, entre las cuales Balmaceda Toro toma parte por la novela realista y critica el romanticismo por imposible y el naturalismo por no ser más que una alquimia positivista que poco tiene que ver con los asuntos humanos. En efecto, después de presentar el romanticismo, su quiebre, y el surgimiento de la novela realista, instala, al final de este proceso, la que por entonces era la moda del momento, el naturalismo. Sitúa a Daudet como el término y culminación del relato realista y a Zola como el iniciador y padre del naturalismo: "Daudet termina donde principia Zola" (p. 179) es la sentencia con que Balmaceda Toro deslinda los límites entre el término de una escuela y el comienzo de la otra. Lo confirma indicando, además, que "[e]n Francia, Zola marca la última de las conquistas, el estremo ${ }^{3}$ sectario de la escuela, así como Alfonso Daudet es ese difícil término medio, en que, como dice un escritor, principia la realidad i concluye la novela" (Balmaceda Toro, 1889, p. 179). No se necesita mucho para advertir las simpatías del joven líder chileno de las tertulias del Palacio de La Moneda hacia el escritor provenzal y el rechazo que siente hacia el proyecto de Zola. Este será un rasgo que, para comenzar, indica cómo Zola despertó también en Chile simpatías y

\footnotetext{
${ }^{3}$ Se respeta la grafía original, así como su ortografía acentual y literal.
} 


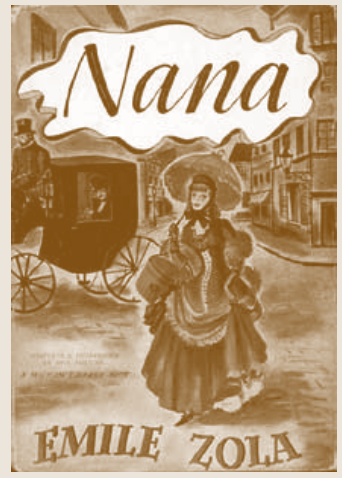

antipatías. En el caso de Balmaceda Toro, entendiendo su cercanía hacia el modernismo, es comprensible que el lobreguismo zolaniano le produjera tal reacción. Ahora corresponde ver cuáles son los fundamentos que ofrece.

Lo primero que destaca de la estética de Zola es que, como dice Lemaitre, "escribe con cielo de otoño. Nunca se divisa el sol en sus obras" (p. 197). Además, que su defecto estriba "no en la pintura de sus personajes, sino en el tono de su obra, en el conjunto de sus observaciones, hipotéticamente reales" (p. 197). Rechaza el cientificismo de una metodología que aspira a la simplificación de la realidad, llevándola por el camino de una pretendida rigurosidad que no alcanza para delinear los pliegues y matices que las leyes positivistas desconocen:

no es dable, como lo hace el autor del Germinal, que de una familia ficticia, adornada de cualidades i de defectos mui pronunciados: en una palabra, [que] de la hipótesis de una novela, se pueda sacar conclusiones científicamente verdaderas, jeneralizar estas conclusiones, hasta escribir la historia de una jeneracion compuesta de centenares de individuos ( $\mathrm{p}$. 179)

Es decir, una estética que, además de oscura, es ineficaz frente a la realidad.

Con ironía, Balmaceda Toro no quiere "desconocer los méritos de hombre tan distinguido" (p. 192) ni tampoco su capacidad de abarcar la realidad con visión integradora, un don consistente en "una vista dominadora i un talento incomparable de unidad" (p. 192). Con la misma ironía, tampoco quiere desconocer "su escuela, que en el porvenir será el álbum anatómico mas perfecto que nuestro siglo abandone al futuro" (p. 192). Pero sí quiere dar "cuenta de sus extravíos" (p. 192), lo cual significa evaluar las debilidades de la escuela naturalista. Para esto, describe primero la metodología zolaniana:

Las novelas todas de Zola, forman una cadena sucesiva que nace de una tésis que el novelista ha desarrollado por todos los caminos imaginables, teniendo en vista al escribirlas la unión que entre ellas debe dominar, como conjunto de ideas sociales i como prueba de un hecho que se reproduce en cada una de ellas (pp. 192-193).

Como ejemplo de ese tratamiento narrativo, revisa la saga de la familia Rougon Macquart, propuesto por Zola como un estudio de una familia durante varias generaciones y ramas derivadas. El objetivo es demostrar cómo en todos los descendientes, de un tipo o de otro, se reproducen incli- 
naciones y vicios heredados de los padres, toda una serie de "individuos, en los cuales se ve la reproducción de las mismas cualidades de carácter, de las mismas pasiones, de las mismas miserias, que imperan en los projenitores de la familia" (p. 193). Finalmente, independiente de las cualidades humanas que uno u otro descendiente puedan tener, el resultado general es "una ecuación terrible de miseria que, en todo caso, se resuelve en la muerte o en el suicidio" (p. 195).

En Chile, hubo una novela que se consideró naturalista. Su nombre, Juana Lucero (1902). En esa novela de D’Halmar se proponía que otro de los determinismos zolanianos, a saber el determinismo social, termina por aniquilar al personaje. Sin embargo, D'Halmar decide, al final, salvar a Juana escogiendo para ella la locura en vez del suicidio o la muerte. Esta locura, sin embargo, no es instalada en el contexto de la narración como una condenación o un destino abyecto, sino como una liberación. Mejor se puede entender esa locura si se lee el drama Lázaro (1906) del mismo D’Halmar; allí se puede ver que la enajenación es un recurso de liberación ante la oscuridad del mundo. Se la vincula a la poesía, a la videncia y a la ensoñación; se la ve como un espacio donde se revelan los sabios, los profetas y los poetas; es un lugar, dentro del mundo, donde los iluminados, los sufrientes y los soñadores pueden encontrar refugio. He aquí un ejemplo de recepción explícita de Zola en Chile (pues Juana adopta el nombre de Naná, personaje de una de sus novelas), pero, al mismo tiempo, variación y asunción de un tono propio. Más disciplinados en el seguimiento de alguno de los determinismos zolanianos son Edwards Bello (determinismo social), Orrego Luco (determinismo genético), Mariano Latorre (determinismo ambiental). Sin embargo, ninguno de ellos abordó un proyecto monumental como el de Balzac, en el plano realista, o Zola en el naturalista.

Para Balmaceda Toro, Zola tiene "el mérito de la percepción" (p. 186), pero adolece de postular una doctrina que "desconoce las variedades del arte, aceptando solo aquellas en las cuales cabe el procedimiento de la escuela" (p. 186). En virtud de tal necesidad metodológica, aventura que "quedan condenadas la arquitectura, la cerámica, la jardinería i otras manifestaciones del arte" (p. 186).

La escuela de Zola, en síntesis, "ha perfeccionado la novela contemporánea, prestándole, ántes de todo, la verdad de los hechos, i por medio de las ciencias, el conocimiento de los caracteres i el estudio de las pasiones" (186), todo un intento de llevar las ciencias a la novela. Evidentemente, la autonomía de las artes queda supeditada al dictamen del positivismo; un nuevo servilismo que cercena las posibilidades del arte, y le plantea una

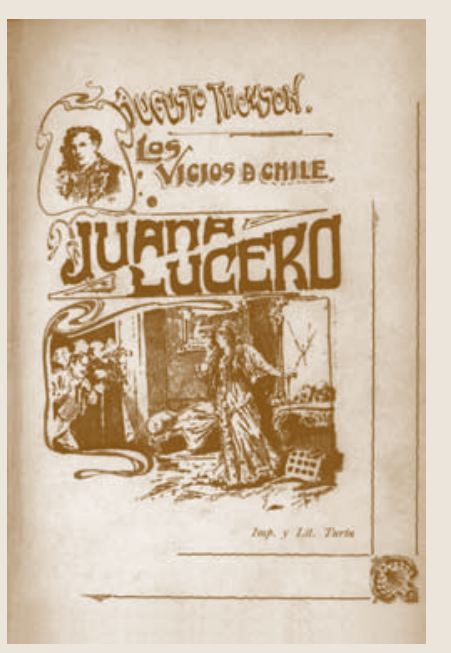


nueva obediencia, en sustitución de la que en un tiempo fuera obediencia a la religión, a la filosofía, e incluso a la educación.

\section{ZOLA EN LAS REVISTAS LITERARIAS}

Después de 1900, la percepción de la obra de Emile Zola en Chile es muy distinta. Y, como ocurrió con Tolstoi, la admiración que suscita tiene dos frentes: uno relacionado con su vida y otro con su obra y su doctrina estética.

En 1902, la revista Pluma i lápiz dedica dos artículos a la muerte de Zola, dichos documentos son útiles para barruntar sobre el balance al que se había llegado en un lejano país sobre el peso de un escritor que había logrado tanta popularidad en el mundo y que tantas odiosidades y afectos había alcanzado.

En el número 94 aparece, de un cronista que se denomina A.P.M., la columna "Zola". En ella abunda el tono elegíaco laudatorio característico de la época y de las circunstancias, suficientes como para ponderar lo más posible el artículo, sin, por supuesto, desacreditar su sinceridad. Expresiones de lamentación ante la muerte de Zola, como "se van los grandes", "tremendo dolor", "esas dos palabras [Zola muerto] han sacudido como una descarga eléctrica toda la humanidad”, “... la grandeza, la casi santidad de la emoción aun no osa quitar el dedo de los labios” (p. 6), etc., señalan la dominante del texto, expresando el alto significado que se le daba a la ausencia del narrador de Naná.

A.P.M. valora en Zola algo más que el escritor: "No era un literato. Un literato solo escribe" (p. 6). Y este compromiso vital al que alude, lo confirma diciendo: "I he aquí este santo Hércules descendiendo al centro mismo de las grandes batallas de la vida moderna para batirse por el triple i glorioso lema de lo verdadero, de lo bello i de lo bueno, aplicado en su mas amplio i elevado sentido" (p. 6). En medio de expresiones que unen categorías cristianas, "santo", con personajes paganos, "Hércules", y con categorías aristotélicas, "verdadero", "bello", "bueno", se delinea el perfil de una especie de santidad moderna, la cual confirma con otras expresiones: "Su jenio era una fuerza de la naturaleza. / I era una fuerza benéfica" (p. 7), "oigo el latido acompasado de su pecho con la misma impresión con que oiría el retumbar de la catarata del Niágara" (p. 7). Solamente le parece comparable a "aquel venerable patriarca del alma rusa que allá en los confines de la estepa helada se ha batido i aun se bate contra los años i la muerte, no como un Príamo 
encorvado i ciego sino como un Aquiles jóven i victorioso" (p. 7). Grande como Tolstoi, Zola parece como una colosal columna en Occidente que sostiene al universo, mientras su contemporáneo ruso hace lo mismo en la Europa Oriental. La grandeza de Zola, según A.P.M., está en la conjunción de su doctrina y de sus sentimientos: "este gran corazón i este gran cerebro" (p. 7). El espesor de su existencia es similar al mayor de los escritores griegos: "Figuraos que Homero desapareciese de la antigüedad" (p. 7). Y concluye su elegía con una rogativa que resume todos sus sentimientos hacia el escritor francés, y toda la admiración que le inspiraba:

En nombre, pues, del Arte, de la Vida, de las multitudes ateridas o enlodadas de los Rougon Macquart, de los caídos de la Debácle, en nombre del obrero de blusa pidiendo pan en Jerminal o de Nana, coronada sepulturera, amortajando almas i cuerpos podridos bajo el oro i la seda; en nombre de la Bestia Humana arrastrándose en Pont-Bouille o alucinada, implorante en Lourdes, en nombre de Dreyfus vindicado, en nombre del progreso, de la vida moderna, en nombre de la intuicion clara del porvenir entrevista en la Jerusalen celeste de su Fecundidad, en nombre de lo que le deben los hombres, en nombre en fin de su obra, yo me dirijo a todas las naciones, a la humanidad i pido para él, duelo, profundo duelo, el duelo del corazón (p. 7).

De este modo termina el dolor, la memoria, la convocatoria, el deseo que quiere expresar el cronista del año 1902 en la revista Pluma i lápiz. Sería inoportuno desechar este texto sin observar la información valiosa que aporta tanto acerca del estilo como de contenido. A saber: sobre el estilo, valoración de una retórica ampulosa, que indica rasgos modernistas, pues se eleva la imagen de Zola a tonalidades homéricas, hercúleas y pelidas. A nivel de contenidos, se destaca la sensibilidad por el Zola que escribió novelas ambientadas en situaciones sociales abyectas y el que defendió a Dreyfus para vindicar la imagen de un inocente. El rescate de lo social en un empaque ampuloso configuran la novedad del texto, lo cual habla de la retórica recurrida en aquel tiempo en Chile y en Latinoamérica, cuando no se quería renunciar a un lenguaje cargado de resonancias clásicas, e incluso bíblicas, para hablar de realidades contemporáneas que llamaban la atención de la sensibilidad social a la que había despertado el campo literario desde la lectura de los realistas y naturalistas europeos.

Con una redacción más estilizada, la columna del número 100 de Pluma i lápiz (pp. 5-6), escrita por un autor desconocido, pues sólo tiene como firma el nombre de la revista, se retoman aspectos de la vida de Zola. Comienza relatando cómo la muerte del escritor ha impactado en todas partes 
y cómo se han recordado "sus difíciles comienzos en la vida, como humilde empleado de librería, su paso por el diarismo militante, sus encarnizadas luchas literarias, el éxito de sus libros ante el público, su fracaso ante las academias clásicas" (p. 5). En particular, en medio de esa carrera literaria, se destaca su compromiso con el affaire Dreyfus:

I al trazar la luminosa carrera de Zola, todos los biógrafos han debido detenerse ante el hecho histórico i culminante de su vida, cuando el escritor dueño del triunfo, con un reposo ganado, baja con una noble i sobrehumana espontaneidad al medio de los riesgos i peligros de un enconamiento de pasiones, entra en el affaire Dreyfus i con su famoso J'acuse del 13 de enero de 1898 provoca delante de la Corte de Justicia el ruidoso proceso que termina con su condena a un año de prisión, a tres mil francos de multa i a la suspensión de su grado de oficial de la Lejion de Honor (p. 5).

Se destacan también los rasgos físicos que señala un retrato que en la misma columna se expone, viendo en ellos las señales de su nobleza humana. Al mismo tiempo, se refiere a la importancia que tuvo su compañera de vida, con quien mantuvo una relación de más de treinta años.

Importante es también la mención que hace a la casa que compró y agrandó en Medan, en donde tendría lugar la redacción de varias de sus novelas "publicadas bajo el nombre de las Soirées de Mèdan en que colaboraron sus principales discípulos, entre ellos Guido de Maupassant" (p. 5). Concluye, finalmente con un pasaje del Diario de los Goncourts:

El amor o la muerte, cosa curiosa, son siempre el tema de nuestros postres. Zola cuenta que habiendo muerto su madre en Médan i siendo mui estrecha la escalera, fué necesario bajarla por una ventana, i que nunca ha podido fijar los ojos en esa ventana sin preguntarse cuál de los dos va a bajar por ella, si él o su mujer... (p. 6),

cuestionándose finalmente si, en el momento de su muerte, tuvo presente Zola aquel pensamiento, ya no como como un temor, sino como "una pesadilla que avanzaba i llegaba como una monstruosa realidad" (p. 6).

Esta segunda columna de la revista Pluma i lápiz, deteniéndose como la anterior en la vida de Zola y en su misteriosa muerte, recorre, entonces, los rasgos más relevantes de su biografía, destacando el valor de una vida excepcional que, más allá de las historias que escribió, merece ser contada como una historia en que se observa una férrea consecuencia entre sus escritos, su sensibilidad y sus actos. 
Continuando con esa semblanza humana en que se detenían los cronistas de los primeros años del siglo XX, se puede citar el comentario que hace Ignacio Pérez Kallens en su columna "Mis idolatrías", publicada en el número 86 de Instantáneas de luz i sombra, 1901. En ella, habla Pérez Kallens de los odios de Zola, los cuales justifica como explicables, pues

[é]l ha sido durante treinta años el león acorralado por las infames jaurías que forman -cuando los une el mismo fin perverso- los imbéciles y los malvados: él ha sido el blanco eterno de las flechas lanzadas por la vieja sociedad que se derrumba y por el viejo dogma que cae hecho pedazos; él ha sido la presa constante de todas las injusticias por él combatidas, de todos los vicios desenmascarados por él, de todos los corazones cobardes y de todas las almas rastreras. No es extraño, pues, que tenga sus odios (p. 13).

Y resulta que, precisamente en la misma revista (ILS), se había publicado un curioso texto de Rubén Darío, quien, hablando de una audiencia en que pudo saludar y contemplar al Papa León XIII, pareciendo no haber motivo para ello, lo compara con Emile Zola:

El viejo feo de Zola, el avaro de los decires de antecámara, el sinuoso ajesuitado ó jesuita del todo, el contemporizador con la democracia moderna, el papa de los periódicos, desapareció, se borró por completo de mi memoria, para dar lugar al papa columbino, al viejecito sagrado que representa veinte siglos de cristianismo, al restaurador de la filosofía Tomística, al pastor blanco de la suave sonrisa, al anciano paternal y al poeta (p. 3).

El rechazo (¿odio?) con que Darío habla de Zola se hace compatible con las críticas que Balmaceda Toro había hecho en su tiempo, compañeros ambos en la aventura modernista cuando éste se hallaba en sus inicios. Y la admiración con que habla del Papa restaurador parecen ser la materialización del rechazo que experimenta el escritor naturalista por parte de los que admiran lo que Ignacio Pérez Kallens llamaba como "el viejo dogma que cae hecho pedazos". La alusión de Darío a Zola, hablando de León XIII, deja de parecer extraña, como una obsesión personal contra él, si se piensa que ese comentario ofrece luz sobre el hecho de que Zola, más que un escritor, es el representante de una doctrina que amenaza contra el antiguo orden; con un materialismo cientificista o un pragmatismo "ajesuitado", propone una metodología, unos principios y una narrativa que, más allá de denunciar la realidad, socavan los cimientos mismos de la civilización cristiana. Vista así, 


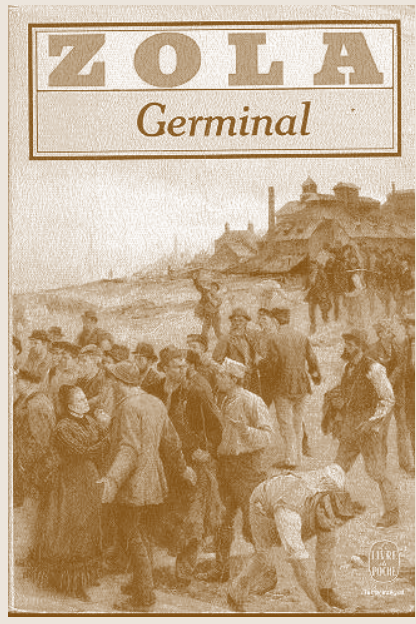

la comparación deja de ser baladí ya que revela, de algún modo, una señal de cambio que indica la instalación de la modernidad. A pesar de lo que el mismo Darío habría querido, está dando evidencias -por vía de oposiciónde que Zola es el pontífice de los tiempos modernos.

Se confirma con estas citas que la preocupación de las revistas de la época se centraba más en el hombre, el ideólogo, el fundador de una escuela, el testigo de su tiempo y el protagonista de algunas luchas que en el escritor. Quizás no fuera necesario, pues el clima literario de entonces estaba marcado por sus lecturas. ¿Quién podría necesitar comentarios sobre su estética narrativa, si ya era conocido y leído por seguidores y contrincantes? Por este motivo, es posible postular que las huellas literarias zolanianas son más advertibles oblicuamente en algunos comentarios o textos relacionados con otros escritores. Se citan a continuación tres ejemplos.

En el número 28 de Instantáneas de luz i sombra (1900), el columnista de pseudónimo Nadir comenta sobre uno de los colaboradores de la revista, Augusto G. Thomson, los cuentos que ha escrito y el proyecto narrativo que está desarrollando. Destaca de él que "se revela en sus líneas un médico de almas y su bisturí penetra tan hondo que á veces asusta" (p. 5), mostrando con ello su capacidad de observación y de vivisección de la realidad. Inmediatamente lo compara con el autor de Germinal, postulando que está a punto de "creer que en muchas ocasiones su pintura realista lo convierte en un ser cruel. Zola, a la edad de Thomson, era acaso más humano, ó más bien dicho, tenía más piedad con los heridos, con los enfermos del pudridero humano" (p. 5), aludiendo a la crudeza con que describe las realidades que pasan por su pluma. También dice que Thomson tiene "sus lobos que lo acechan" (p. 5), suerte de todo aquel cuya obra no está destinada a ser ignorada. En estos conceptos, se ve la imagen de Zola en el escritor chileno; sin embargo, Nadir alude a cualidades que lo hacen distinto:

Es poeta en la concepción de sus ideas, siempre nuevas, siempre originales; es músico, porque su estilo es correcto y galano, y es pintor, porque su pluma sabe dar vida, luz i colorido á los cuadros de su inteligencia (p. 5),

es decir, creador de una prosa que no sólo se entretiene en describir oscuridades sino también en señalar un cierto brillo, belleza y color a sus narraciones. Thomson sería, entonces, el punto donde se encuentra el modernismo heredado del grupo de Balmaceda Toro (y Rubén Darío) y la estética social propia del realismo y del naturalismo. Un hibridismo de este 
género puede parecer indisciplinado o flirteo irresponsable, pero es la nota ineludible que lo emparenta con las tentativas narrativas latinoamericanas y de la chilena, de la cual él es uno de sus fundadores.

Como testimonio de la cercanía de Augusto G. Thomson al estilo de Zola hay un relato titulado "La Rapiña", publicado en 1901, en el número 67 de Instantáneas de luz i sombra. Trata de una muchacha que merodeaba en el entorno de la vereda del Club de Septiembre, ofreciendo diarios y discutiendo con insultos y groserías con los hombres que trabajaban en el sector: guardianes, cocheros, sirvientes. La que el narrador califica como "larva de mujer", con características de "mujer enclenque", de "ojos insolentemente provocativos" y con un hablar ágil en que no faltaban "palabras de conventillo" (p. 1). El calificativo de "Rapiña" le venía por las garras que sacaba cuando alguno de los suplementeros la agredía con bromas o pesadeces. De ese modo, ella se hacía valer entre ellos como una más, recurriendo a las artes del desenfado con el fin de ganarse el respeto de quienes podrían agredirla:

Ahí, en las clases prostituidas, el vicio, el relajamiento, la desvergüenza, infunden el respeto y hasta el cariño de los cofrades; se admira á un depravado, como los buenos admiran á un virtuoso; en el mundo todo es relativo y, los infelices, colocados en el nivel de la infamia, naturalmente sólo á la infamia son dignos de comprender y de estimar (p. 1).

Todo un cuadro del bajo mundo al que pertenece La Rapiña y en el cual debe sobrevivir con las estrategias de la naturaleza, lo cual viene a formar, en sujetos como ella, seres dotados de una alta resistencia física al mismo tiempo que de una baja calidad moral, necesaria, por cierto, para no sucumbir a los desafíos del medio. La diferencia que hay entre Juana Lucero y La Rapiña es que la primera, a pesar de haber tocado fondo, no tenía resortes para resistir y superarse ante la abyección; su bondad, "la purisimita", se imponen y por eso termina enajenada. La Rapiña, por medios que el narrador interroga sin saber responder, ha recibido alguna formación del medio; las circunstancias, las personas con que ha vivido la han hecho para la resistencia, y su semblanza final de residuo humano resulta ser el fruto de tal educación:

¡Daba gusto verla con su cara de virgencita viciosa, al viento sus harapos, sin más adorno que la cinta de seda - trofeo de hurto - que la adornaba, el pelo en desorden, y los tolondrones de papel que se encajaba en el pecho para hacer apariencia de lo que aun no podía guardar!.. (p. 1).

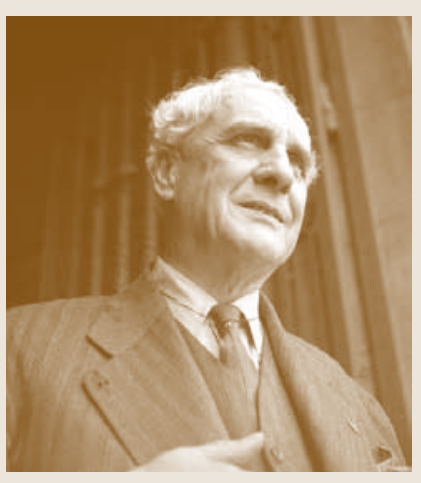

A. G. Thomson 


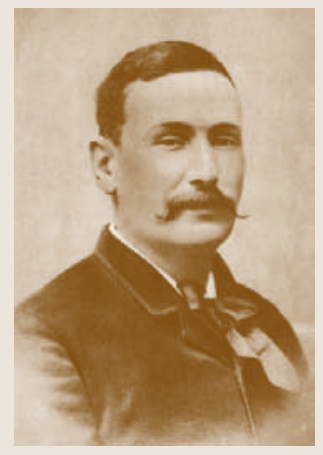

La Rapiña responde a una galería mínima de personajes que en escritores como Zola habrían alcanzado quizás una estatura novelesca, pero que en los relatos de los escritores chilenos como Thomson alcanzan a aparecer apenas como "larvas de personajes", a los cuales, sin embargo, a pesar de no tener un gran desarrollo, no les faltan los rasgos generales propios de una literatura que intenta reflejar cómo el medio influye en la formación de los seres humanos.

También en 1901, en el número 48, aparece un artículo firmado por Buenafé, uno de los articulistas de Instantáneas de luz i sombra. Lleva por título, simplemente, "Benito Pérez Galdós" y, hablando del proyecto del escritor español destinado a "pintar las miserias del mundo y sus consecuencias" (p. 4), destaca el sentido que le ha dado Zola a lo que algunos pensaban como un escándalo por dibujar tan crudamente la realidad. Las críticas llegaban a señalar que dicha escritura pecaba incluso de "pornográfica", adjetivo que, a la luz de la crítica literaria posterior, resulta impertinente y exagerado. Sin embargo, ahí estaba, como reacción significativa que justificaba algunos de los ánimos exacerbadamente contrarios a la narrativa zolaniana y a la de quienes lo seguían, Pérez Galdós, entre otros. Según Buenafé, sin embargo, hay una cierta contradicción en los propósitos del escritor francés, la cual consiste en que no todos sus personajes responden a la predicación que ha hecho con respecto a su escuela; a saber:

yo os pinto el vicio para que lo conozcais, lo pinto lo mejor posible para que la imaginación lo siga sugestionada por las bellezas de la descripción y la realidad, quiero señalaroslo, mas no que lo sigais y he aquí mi programa: cuál farmacéutico literario rotulo para que no se os infiltre en vuestro ser por la ignorancia y sin saber ni encontrar barrera que oponerle, en una palabra pongo al frasco del sublimado corrosivo la etiqueta con la calavera y el veneno que os hace cuidar del contenido con todos los cuidados que no tendríais si ignoráseis que el líquido era aquél (Zola, citado por Buenafé, p. 4).

Buenafé, después de afirmar que ésta es "la ciencia de la escuela naturalista, de la buena, de la bella escuela" (p. 4) y de desdeñar a aquellos autores que se separan y "complácense en describirnos vicio tras vicio sin el fin moral á que tiene derecho la humanidad" (p. 4), señala que al propio Zola le sucede que algunos de sus personajes no cumplen con la persecución de sus principios,

muchos de sus personajes, completamente inmorales sin que el lector sienta por ellos la censura que reclama la noble escuela, más de una 
imaginación enfermiza querría ocupar el lugar que se le ha destinado á aquel ángel del mal (p. 4).

Y agrega que en esto Galdós supera a Zola, pues, consecuente con la disciplina naturalista, es capar de descender a "los antros de perdición" exponiendo toda suerte de vicios y corrupciones, pero siempre con una inteligencia tal que "nos llega a hacer aborrecer aquello mismo que con colores tan atrayentes y sin pizca de mojigatería se ofrece a nuestra imaginación. He aquí el triunfo de Galdós" (p. 4).

Esta página crítica, amén de valorar la consecuencia estética de Galdós por sobre las "caídas" de Zola, ilustra la concepción de la literatura en su fase moderna, es decir, como depositaria de un contenido que debe dar cuenta de la "verdad" y, por tanto, transformarse en un vehículo de corrección de los errores. La literatura no solo denuncia, no sólo describe la realidad, sino que educa, conviertiéndose en una norma de funcionamiento para la sociedad. Cuando un escritor abandona ese compromiso, entonces, no hace "buena literatura". Este baremo crítico asigna gran importancia a la primacía del autor, el cual aún no ha muerto; el que no ha nacido todavía es el lector, o, por lo menos, es considerado un infante que necesita ser guiado por una conciencia rectora, a través de un tipo de relato que tiene mucho de apólogo, y por un autor que tiene más de docente que de contador de historias.

\section{ZOLA DESPUÉS DE ZOLA}

Hablar de Zola en Chile significa, bajo muchos aspectos, hablar de Augusto Thomson (D'Halmar). D'Halmar es una pieza clave en la comprensión de los fenómenos culturales y literarios de la primera mitad de la década 19001910. Su figuración en el Ateneo era tan importante en esos tiempos que los jóvenes lo llegaban a vitorear con exclamaciones como “¡Viva el Zola!, ¡Viva el Loti!”. Contradictoriamente, se lo veía como seguidor por igual del naturalismo y del exotismo; no importa por ahora, porque ese no es el tema de discusión. Lo que sí importa es que se lo veía como quien encarnaba la estética del creador de Nana, sobre cuyo modelo D’Halmar escribiría su Juana Lucero. Por este motivo, no se puede concluir un artículo sobre Zola, como sobre Tolstoi, Daudet y otros más, sin acudir a la opinión de D'Halmar, testigo eficiente de la recepción literaria de los escritores que marcaron el proceso de autonomización del campo literario en Chile. Para hacerlo, basta recurrir al capítulo “Zola y la novela social”, publicado por D’Halmar en 
Los 21 (1948). En estos comentarios, aunque escritos en una fecha indeterminada, se observa la visión final del escritor maduro (D’Halmar contaba con 66 años a la fecha) sobre los veintiún escritores que influyeron en él y, por extensión, en la generación de 1900.

La admiración de D'Halmar hacia Zola es indiscutible. Lo admira como hombre y como escritor. Destaca sus orígenes, su compromiso con el caso Dreyfus, y su papel en la instalación de la "revolución de una nueva forma literaria llamada Naturalismo" (p. 106). Con él, agrega, "[e]l arte social acaba de nacer" (p. 106).

D'Halmar, en el contexto de una reflexión general sobre la vida de Zola, destaca su compromiso con la verdad. "Mettre en marche la Verité" fue su lema "al lanzar al mundo el 'Yo Acuso' que produjo la revisión del proceso Dreyfus" (p. 111), pero no sólo ahí, en ese compromiso vital, sino en el desarrollo de una obra que se proponía buscar en las leyes científicas una explicación de la realidad es donde Zola expresa el ímpetu de su compromiso, que no era otro que poner la literatura al servicio de la renovación de la conciencia humana, en donde aflorarán, según el escritor chileno, las virtudes evangélicas de la justicia, la fraternidad y, sobre todo, el amor, "[p] orque, como San Pablo dice 'muchas son las virtudes, pero la mayor de todas es la Caridad"' (p. 112).

\section{CONCLUSIONES}

En las revistas literarias revisadas, poco más de lo dicho hay sobre Zola. En estos ejemplos se puede observar que no preocupaba sólo su obra sino también su vida; ambas, sin embargo, suscitan afecto y desdén. En algunos casos, la admiración se convierte en idolatría, así como en otros el rechazo se asemeja al odio. Zola no suscita indiferencia y él ha supuesto el punto en donde se encuentran para litigar, confrontarse y beligerar dos visiones de mundo que representan, a su vez, el cambio de paradigma entre el "viejo dogma" y la nueva ciencia; los odios son justificados pues muchos sienten ver que el mundo en que habían sido formados y en el cual tenían intereses que defender inevitablemente amenazaba con derrumbarse; es, en el fondo, el conflicto entre premodernidad y modernidad.

Esta confrontación presenta básicamente dos actores importantes. Pedro Balmaceda Toro, a inicios del proceso de autonomización del campo literario, quien discrepa de la escuela naturalista y de la propuesta de Zola. Lo hace porque significa el término cientificista de la escuela realista, la cual representa para él el paradigma de la verdadera literatura, conside- 
rando que lo que hace Zola es artificializar el curso de las cosas; la vida no funciona con el rigor de un sistema y la belleza del arte, que consiste en referirse a lo vario de la existencia, lo que le da gracia y colorido, termina perdiéndose en una estética del rigor. El segundo actor es Augusto Thomson (D’Halmar) quien, aparte de ser aclamado por décadas como el “Zola chileno", expresa sus sentimientos de admiración hacia aquel que considera como el iniciador del "arte social".

Con respecto a Zola, hay que decirlo, las revistas del período 1900-1910 no son muy generosas en información. El es un personaje instalado, y hablar de él, aparte de los homenajes necesarios motivados por su muerte, parece ser una tarea ya cumplida. Habría quizás que buscar en materiales escritos cuando recién era descubierto entre nosotros. Los comentarios de Balmaceda Toro son iluminadores en ese sentido, puesto que él de alguna manera sintetiza la recepción frente al escritor francés.

¿Qué queda como conclusión de todo este proceso de recepción? Primero, Zola como un escritor que propone la consumación de la escuela realista con el naturalismo; valorado como el fundador de una escuela, pero discutido en su metodología. En una segunda fase, el hombre que se compromete con su palabra, y el que reúne en torno a sí una escuela de seguidores, sobre todo en su casa de Medán. Para algunos ya suscita una verdadera idolatría sin discusión; para otros, rechazo virulento. Zola es ya considerado no sólo como el creador del naturalismo, sino como el punto donde un viejo orden cae y uno nuevo comienza a surgir; es "el papa de los tiempos modernos”. En una tercera etapa, cuando D’Halmar habla de él hacia 1948, el discurso sobre Zola está ya cristalizado y, aunque probablemente a esas alturas nadie escriba como él, queda como el principal exponente de la cuestión social en literatura; sin duda, uno de los que influirá más en los contenidos de la producción literaria chilena de las primeras décadas del siglo. Queda la idea de que él fue fiel a su lema y que todo el que siga sus pasos tiene como tarea "poner en marcha la verdad".

\section{REFERENCIAS}

Anónimo. 1902. "La muerte de Emilio Zola”. Pluma i lápiz, 100, 5-6.

A. P. M. 1902. "Zola”. Pluma i lápiz, 94, 6-7.

Balmaceda Toro, Pedro. 1889. Estudios $i$ ensayos literarios. Santiago: Imprenta Cervantes.

Buenafé (pseudónimo). 1901. "Benito Pérez Galdós". Instantáneas de luz i sombra, 48,4 .

Darío, Rubén. 1901. “Ante León XIII". Instantáneas de luz i sombra, 82, 1-3. 
D’Halmar, Augusto. [1948] 1969. Los 21. Santiago de Chile: Nascimento.

Nadir. 1900. "Nuestros colaboradores. Augusto Thomson". Instantáneas de luz i sombra, 28, 5-6.

Pérez Kallens, Ignacio. 1901. “Mis idolatrías”. Instantáneas de luz i sombra, 86, 13-14.

Thomson, Augusto. 1901. "La Rapiña”. Instantáneas de luz i sombra, 67, 1-2. 